\title{
Smart Bio-Polymer From Tapioca Sago Possessing Novel In-Built Filmability By Synergistic Approach Using Film Initiator
}

\author{
Kirti Singh* and Satheesh Madhav NV \\ Faculty of pharmacy, Novel Drug Delivery Research Lab, DIT University, India
}

Received Date: September 07, 2018; Published Date: October 09, 2018

*Corresponding author: Kirti Singh, Faculty of pharmacy, DIT University, Dehradun, Uttarakhand, India; Tel: +919756153879;

Email: kirti_29singh@yahoo.in

\begin{abstract}
The main objective of this research work was to isolate a bio-polymer from Tapioca sago and formulate bio-flexy films. A novel bio-polymer was isolated from a natural and edible source Tapioca sago and using the bio-polymer five bio-flexy films of different ratios (i.e. 1:1, 1:2, 1:3, 1:4, 1:5) were formulated using a model drug i.e; Atorvastatin and other co-processing agents. The isolated bio-polymer was subjected to various analytical parameters. The drug-excipient compatibility study was performed using UV and TLC method. The formulated bio-flexy films were evaluated for various parameters like weight, thickness, content uniformity, surface $\mathrm{pH}$, folding endurance, and in-vitro drug permeation. The formulation AT4 (containing 1:4 bio-polymer) was found to be the best formulation having R2 value 0.995 with zero order as best fit model. The results obtained concluded that bio-polymer isolated from Tapioca sago can be used as a film forming agent and further can be utilized in various formulations.
\end{abstract}

Keywords: Bio-polymer; bio-flexy films; Tapioca sago; Atorvastatin

\section{Introduction}

Tapioca Sago is known as sago (sabudana in hindi or javvarishi in tamil) in India. It is a product, prepared from the milk of Tapioca Root. Its Botanical source is "Manihot Esculenta Crantz Syn. Utilissima" belonging to the family Euphorbiaceae. It is a good source of proteins, carbohydrate, iron, calcium, folic acid, vitamin $\mathrm{B}$, and contains low levels of potassium, copper etc. The health benefits of Tapioca sago include weight gain, low blood pressure, improved digestion, fight fatigue, increased bone mineral density, fastens muscle growth, improves nerve function, reduced neural tube defects, and increased blood circulation [1-3].

Atorvastatin is an antihyperlipidemic drug which is a competitive inhibitor of 3-hydroxy-3-methylglutaryl coenzyme A (HMG CoA) reductase. This enzyme is involved in the conversion of HMG CoA to mevalonate which is the rate limiting step in the cholesterol synthesis. According to Biopharmaceutical Classification System (BCS), atorvastatin belongs to class II having good permeability and low solubility. It has low oral bioavailability due to low aqueous solubility and rapid presystemic clearance in the gut wall and hepatic first-pass metabolism. This can be avoided by formulating a formulation for transdermal delivery [4].

Film initiator is an excipient which acts as an enhancer for the filmability property of the bio-polymer. On combining with the bio-polymer, it gives synergistic effect and the films of great quality are obtained. The aim of this research was to isolate a bio-polymer from an edible biological source from Tapioca sago, formulate bio-flexy films, evaluate film forming capacity and determine the suitability of the bio-polymer as a drug delivery carrier.

\section{Materials and Methods}

Atorvastatin was obtained as a gift from A.P.S. Biotech. Pvt. Ltd. Tapioca sago was procured from local market. All other reagents used were of analytical grade.

\section{Extraction of biopolymer from Tapioca sago}

$500 \mathrm{gm}$ Tapioca sago was taken and soaked in $1000 \mathrm{ml}$ of distilled water for $30 \mathrm{~min}$. It was boiled for $2 \mathrm{hrs}$. The gel was prepared, and it was destarchified for overnight. It was centrifuged at $3000 \mathrm{rpm}$ for $5 \mathrm{~min}$ and supernatant was collected which was treated with equal amount of 2-propanone. It was kept in refrigerator for $24 \mathrm{hrs}$. The supernatant was centrifuged at 3000 rpm for $5 \mathrm{~min}$. The bio-polymer was collected and dried. The dried bio-polymer was purified by hot dialysis method. The process was repeated 6 times and the percentage yield was calculated. The purified bio-polymer was passed through $120 \#$ sieve and stored for further use [5].

\section{Characterization of the isolated bio-polymer}

The bio-polymer isolated was subjected to various physicochemical analysis like color, texture, solubility, presence of carbohydrates, proteins and starch; spectroscopic studies like IR, DSC, NMR etc. 


\section{Novel Approaches in Drug Designing \& Development}

\section{Drug-excipient Interaction Study}

Drug interaction with excipients of the formulation was performed by dry and wet method. The drug was mixed with

\section{Preparation of Bio-flexy Films}

Table 1: Formula for Bio-Flexy Films.

\begin{tabular}{|c|c|c|c|c|c|}
\hline Ingredients & AT1 & AT2 & AT3 & AT4 & AT5 \\
\hline Nanosized Atorvastatin $(\mathrm{mg})$ & 10 & 10 & 10 & 10 & 10 \\
\hline Tapioca sago Bio-polymer (mg) & $100(1 \%)$ & $200(2 \%)$ & $300(3 \%)$ & $400(4 \%)$ & $500(5 \%)$ \\
\hline Dextrose (mg) & 100 & 100 & 100 & 100 & 100 \\
\hline Distilled water (mL) & 10 & 10 & 10 & 10 & 10 \\
\hline
\end{tabular}

Bio-flexy films were prepared by solvent casting method. Five formulations were developed with different ratios ,i.e. AT1, AT2, AT3, AT4 and AT5 in the ratios 1:1, 1:2, 1:3, 1:4, and 1:5 respectively. Bio-polymer isolated was accurately weighed in different ratios and dissolved in $10 \mathrm{ml}$ of distilled water at room temperature. Dextrose was added to this solution. Atorvastatin used as model drug was dissolved in little amount of ethanol. The drug solution was transferred into the polymeric solution. It was poured in a petri-dish for natural drying. The dried bio-flexy films were obtained and packed in tightly closed container [6] (Table 1).

\section{Evaluation Parameters for prepared Bio-Flexy Films}

i. Physical appearance: The formulations were visually inspected for various factors like color, clarity, and smoothness in order to ensure the uniformity in physical appearance of the bio-flexy films.

ii. Weight: Three patches $\left(1 \mathrm{~cm}^{2}\right)$ of each formulation were taken, weighed and average weight was calculated $[7,8]$.

iii. Thickness: The thickness of the films for every formulation was measured using a micrometer at three different places and the mean value was calculated $[7,8]$

iv. Folding endurance: Folding endurance was determined by repeatedly folding the film at the same place till it broke. The number of times the film could be folded at the same excipients in the ratios of $1: 1,1: 3$, and $3: 1$. The mixtures were stored at room temperature for a period of 3 days. The dilutions of the mixtures were prepared with methanol and the samples were analyzed by ultraviolet spectrophotometric method [5]. place without breaking was recorded which is known as the folding endurance $[7,8]$.

v. Surface $\mathbf{p H}$ : The individual film was placed in a petridish and moistened with $0.5 \mathrm{ml}$ of distilled water and kept for 30 min. The surface $\mathrm{pH}$ was measured by using $\mathrm{pH}$ meter [5].

vi. Drug content uniformity: The bio-flexy film was dissolved in methanol and volume was made up to $100 \mathrm{ml}$. It was sonicated and kept for 24 hours. $0.1 \mathrm{~mL}$ was withdrawn from this and diluted to $10 \mathrm{ml}$. The drug content was measured by using UV Spectroscopy. This was repeated for all the formulations. From the drug content, percentage drug content was calculated $[7,8]$.

vii. In-vitro drug release study: The in-vitro drug release was carried out by using MS diffusion apparatus. Egg membrane was attached on the donor compartment. The formulated bio-flexy films were adhered onto the egg membrane. The receptor compartment was filled with $13 \mathrm{ml}$ of pH 7.4 buffer solution. Samples were withdrawn completely at regular intervals for $48 \mathrm{hrs}$ and replaced by fresh buffer each time. The samples were analyzed by UV spectroscopy at $246 \mathrm{~nm}$ to estimate the amount of the drug [5].

viii. Stability studies: The formulated bio-flexy films were subjected to accelerated stability studies according to the ICH guidelines for six months [9].

\section{Results and Discussion}

\section{Characterization of the isolated Bio-Polymer}

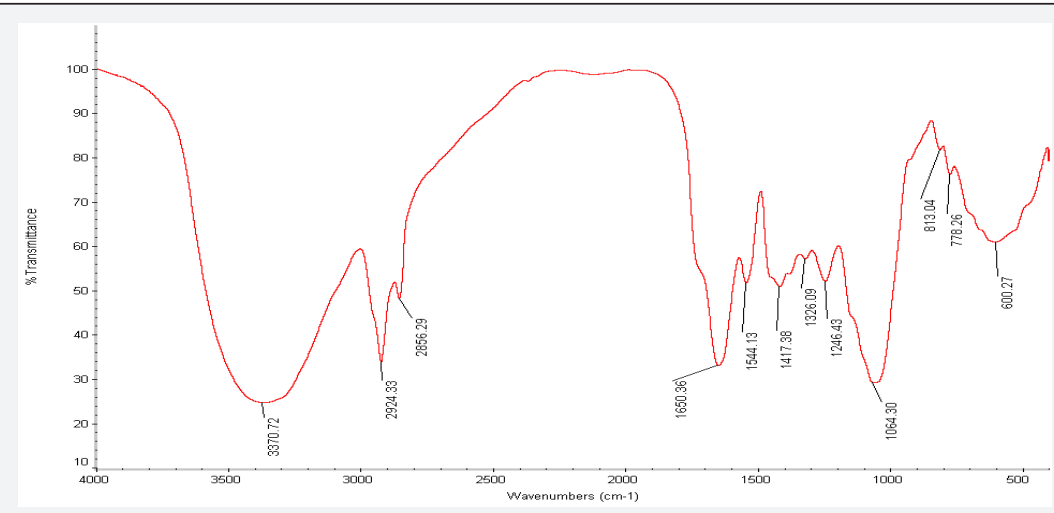

Figure 1: IR spectrum of isolated bio-polymer. 


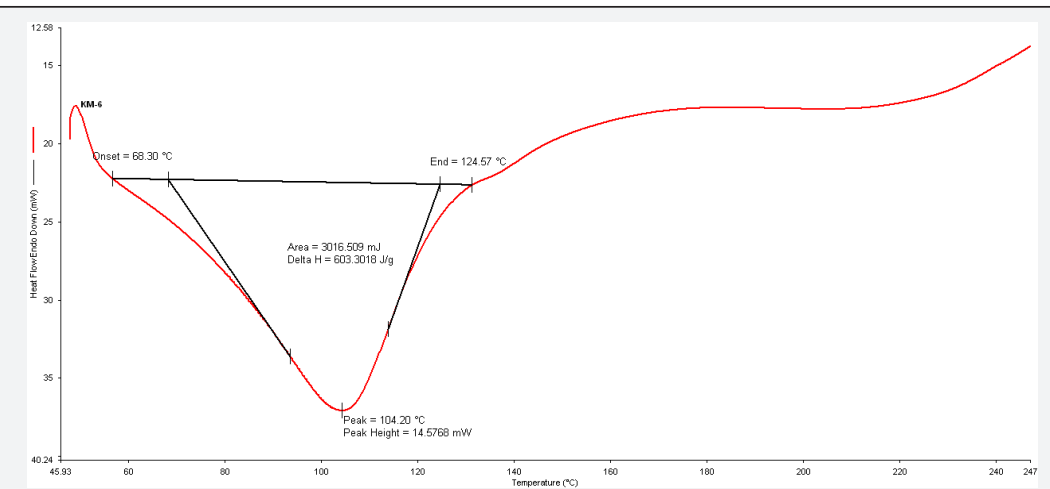

Figure 2: DSC of isolated bio-polymer.

The bio-polymer isolated from Tapioca sago was smooth, amorphous, odourless, and white in color. It was slightly soluble in water. The percentage yield was found to be $4.32 \pm 0.04 \mathrm{w} / \mathrm{w}$. The bio-polymer showed positive test for carbohydrates and proteins which confirms the presence of carbohydrates and proteins in isolated bio-polymer. The color changing point was found to be $260^{\circ} \mathrm{C}$. The IR spectra (Figure 1) of the bio-polymer revealed the presence of aromatic phenols $\left(3370.72 \mathrm{~cm}^{-1}\right)$, alkanes (2924.33 $\left.\mathrm{cm}^{-1}\right)$, alkenes with stretching $\left(1650.36 \mathrm{~cm}^{-1}\right)$, nitro compound $\left(1544.13 \mathrm{~cm}^{-1}\right)$, aromatics with stretching $\left(1417.38 \mathrm{~cm}^{-1}\right)$, sulfone (1326.09 $\left.\mathrm{cm}^{-1}\right)$, thiocarbonyl $\left(1064.30 \mathrm{~cm}^{-1}\right)$. These groups are responsible for bioadhesivity of the bio-polymer. It is essential for a bio-polymer to be bioadhesive for preparing the formulations that are needed to be adhered on the skin for a longer period of time (Figure 2).

\section{Drug-excipient Interaction Study}

During drug-excipient interaction studies, no change was observed in the $\boldsymbol{\lambda}$-max of the drug which revealed that there was no interaction between the drug and the excipients. Thus, drug and the excipients used are non-reactive and compatible with each other.

\section{Thickness, Weight, Folding Endurance and Surface pH}

Thickness of the bio-flexy films AT1 to AT5 ranged from $0.32 \pm$ 0.001 to $0.37 \pm 0.001 \mathrm{~mm}$. The weight of the bio-flexy films AT1 to
AT5 ranged from $22.13 \pm 0.02$ to $30.3 \pm 0.02 \mathrm{mg}$. Slight variation in thickness and weight of the bio-flexy films was found to increase on increasing the weight of the bio-material which ensures uniformity in the formulations. The micro environmental $\mathrm{pH}$ of the bio-flexy films ranged from 6.28 to 6.63 which are nearer to the $\mathrm{pH}$ of the skin. It confirms that the formulations are safe for use as transdermal formulations and they will not cause any irritation effect. Folding endurance of the bio-flexy films ranged from 103 to 129 (times) which is indicative of reasonable flexibility of the bio-flexy films. Increased flexibility leads to increased durability of the formulations.

\section{Drug Content Uniformity}

The range of drug content uniformity for the prepared bio-flexy films was found to be $81.35 \pm 0.32$ to $84.32 \pm 0.25 \%$. No significant difference was observed in the drug content of the prepared bioflexy films which indicated that the drug is uniformly dispersed throughout the bio-flexy films.

\section{In-vitro Drug Release Study}

The drug release of bio-flexy films were analysed by using BIT-SOFT. The graph (Figure 3) was plotted between \%age drug release and time. The drug release profile was found to be in the order AT4>AT3>AT5>AT2>AT1. AT4 (1:4) was found to be the best formulation having $\mathrm{t}_{50} 4.8 \mathrm{hrs}$ and $\mathrm{t}_{80} 28.9 \mathrm{hrs}$. $\mathrm{R}^{2}$ value was 0.995 with zero order as best fit model.

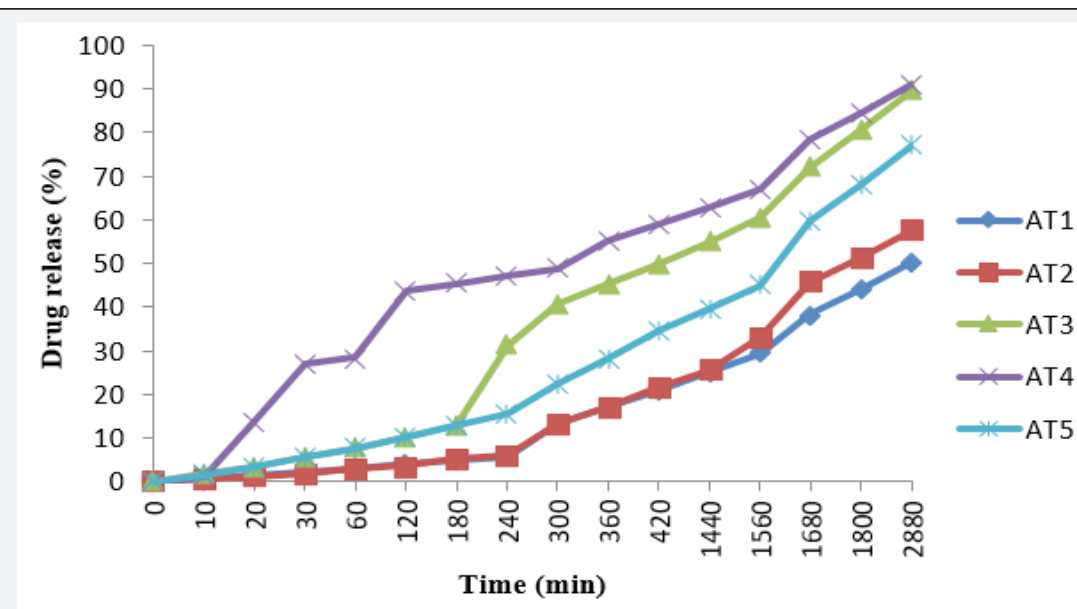

Figure 3: In-vitro drug release. 


\section{Stability Studies}

During and at the end of stability studies, the formulations showed no change in physical appearance and flexibility. They showed insignificant difference for in-vitro drug release. This showed that the formulations were physically and chemically stable during the study.

\section{Conclusion}

In this work, a bio-polymer was isolated from natural source Tapioca sago and using this bio-flexy films were prepared. The bio-polymer isolated was found to be biodegradable, non-toxic, and non-reactive and can be effectively isolated in large quantity. Bio-flexy films are promising formulations for drug delivery. This route by passes the first pass metabolism. Low dose of the drug in the formulations leads to lesser side effects. It is a non-invasive technique as well as no frequent dosing is required thus improves patient compliance.

The bio-polymer showed good film forming and bioadhesive property. Our in-vitro drug release graph showed that the bioflexy films prepared using this bio-polymer depicted good release kinetics of the drug over an extended period. The results concluded that the isolated bio-polymer can be used as a promising excipient for formulating various transdermal formulations.

\section{Acknowledgement}

We would like to show our gratitude to Chairman and Vice Chancellor of DIT University for their valuable support during the course of this research.

\section{References}

1. Introduction of Tapioca Sago (2018) Sago in India, Tamilnadu, India.

2. Health Benefits of Tapioca (Sabudana) (2018) Health.

3. 9 Surprising Health Benefits of Sago (2018) Organic Facts.

4. Elmowafy M, Ibrahim HM, Ahmed MA, Shalaby K, Salama A, et al. (2017) Atorvastatin-loaded nanostructured lipid carriers (NLCs): strategy to overcome oral delivery drawbacks. Drug Deliv 24(1): 932-941.

5. Madhav NS, Yadav AP (2013) A novel translabial platform utilizing bioexcipients from Litchi chinesis for the delivery of rosiglitazone maleate. Acta Pharmaceutica Sinica B 3(6): 408-415.

6. Anisree GS, Ramasamy C, John Wesley I, Koshy BM (2012) Formulation of transdermal drug delivery system of metoprolol tartrate and its evaluation. J. Pharm Sci Res 4: 1939-1942.

7. Murthy TEGK, Kishore VS (2008) Effect of casting solvent on permeability of antihypertensive drugs through ethyl cellulose films. J Sci Ind Res (India) 67: 147-150.

8. Nanda, Sanju, Kamal Saroha, Bhavna Yadav, Benika Sharma (2012) Formulation and characterization of transdermal patch of amlodipine besylate. International Journal of Pharmaceutical and Chemical Sciences 1(3): 953-969.

9. Ezhumalai K, Ilavarsan P, Mugundhan RM, Sathiyaraj U, Rajalakshmi AN (2011) Transdermal patches in novel drug delivery system. Int J Pharm Technol 3: 2402-2419.

\section{Your next submission with Juniper Publishers will reach you the below assets}

- Quality Editorial service

- Swift Peer Review

- Reprints availability

- E-prints Service

- Manuscript Podcast for convenient understanding

- Global attainment for your research

- Manuscript accessibility in different formats ( Pdf, E-pub, Full Text, Audio)

- Unceasing customer service

Track the below URL for one-step submission https://juniperpublishers.com/online-submission.php 